\title{
O Sékulo do Kynema de Glauber Rocha
}

\author{
ARLindo REBECHI JUNIOR ${ }^{1}$ \\ Universidade de São Paulo/Universidade Estadual Paulista
}

ntonio Candido, no jornal Folha da Manhã de 7 de janeiro de 1943, estreava sua coluna crítica com as seguintes palavras: "Do crítico, espera-se geralmente muita coisa. Antes de mais nada, que defina o que é a crítica para ele". O aspecto metacrítico, como ele mesmo ressaltou, era o fundamento e o mais firme esteio do ofício, e trilhava duas questões principais: uma, de ordem pessoal, referindo-se à qualidade de penetração do crítico na obra e em seus respectivos valores; e a outra seria de ordem ética, não bastando ao leitor estar diante de um "homem de boa compreensão, é preciso que sinta o homem de boa-fé". Se o segundo ponto seria mostrado ao longo do tempo por sua coluna que ali se iniciava, o primeiro ponto tinha na pessoa do crítico a base do processo, embora Candido sublinhasse que essa figura do crítico não deveria ser o aspecto principal da crítica, nem tampouco a sua razão de ser. Para ele, em primeiro plano configurava-se a obra em questão.

As idéias de Candido trazem à tona algumas questões importantes, que merecem ser discutidas neste nosso contexto. Primeiro, cabe ao resenhista, ao expor uma obra composta de uma reunião de críticas, o papel de desvendar esses tais aspectos metacríticos levantados acima, sobretudo quando eles não se apresentam de forma tão clara ao leitor. A tarefa, porém, torna-se mais complexa quando a obra a ser resenhada contempla críticas de um longo período e o seu autor, além de ter sido praticante do ofício em questão, foi artista polêmico. É o caso de $O$ século do cinema, de Glauber Rocha, obra

\footnotetext{
${ }^{1}$ Mestre e doutorando em Literatura Brasileira pela FFLCH-USP. Professor de graduação em Comunicação Social da Universidade Estadual Paulista (UNESP).
} 
reeditada em 2006, pela Editora Cosac Naify, sob coordenação editorial de Ismail Xavier, o prefaciador da edição, e de Augusto Massi. O volume complementa a coleção Glauberiana, ainda em processo de publicação, pela qual já foram publicados Revisão crítica do cinema brasileiro (2003) e Revolução do cinema novo (2004).

O século do cinema enfeixa artigos, muitos deles modificados pelo autor, que vieram a público, de diferentes modos, entre os anos de 1956 e 1981, desde as primeiras contribuições de Glauber na imprensa baiana até suas últimas críticas, no ano de sua morte. O livro, assim, ata duas pontas: uma, a do jovem crítico, que já institui o seu território de atuação e de olhares sobre a tradição cinematográfica, alertando seus contemporâneos sobre as vicissitudes da arte cinematográfica em formação; na outra, quem fala é o crítico já maduro, o artista atuante no Brasil e no exterior e o autor de grandes filmes, como Terra em transe e Idade da terra, o qual não economiza farpas para os desafetos nem elogios para os comparsas.

A obra, apesar de dividida de acordo com três campos de atuação do crítico no âmbito estrangeiro - Hollywood, neo-realismo e nouvelle vague -, não deixa de contemplar o diálogo com a própria intelectualidade brasileira. Seria o caso de entender o livro de Glauber não só como objeto do analista do cinema mundial, que demarca um ponto de vista sobre determinada obra ou autor, mas de entendê-lo como um projeto de intervenção, diria engajado, no debate cinematográfico brasileiro, via imprensa. Queria ele, desse modo, adicionar ao eixo de debate latino-americano uma cinematografia da América do Norte e da Europa. O movimento textual de Glauber, em $O$ século do cinema, busca uma análise no sentido da periferia do capitalismo ao seu centro, mas chega ao Hemisfério Norte, não para exaltar a imagem do "colonizador”, mas, sim, para colocá-la em xeque, pensando a própria formação de uma identidade de Terceiro Mundo.

Vejamos o caso do tratamento dado ao cinema produzido em Hollywood, primeira parte da obra. $\mathrm{O}$ autor quer entender as marcas que regem não só esse cinema, mas o tempo histórico americano, como medida para o entendimento das marcas do que ele mesmo denominava como "superestruturaimperialista". Se, para Glauber, Griffith exclui os negros do processo histórico e elege as classes brancas protestantes como construtoras da nação, Chaplin é quem vai desnudar o carnaval capitalista americano, por meio do "ponto de vista do 
personagem oprimido", ressaltando o povo como imagem. Por isso, Chaplin o interessava e era motivo maior de seus elogios. Sobre Tempos modernos (1936), filme deste último cineasta, Glauber vai dizer: "Não morrem os protestos eternos à humilhação que organismos econômicos impõem ao homem" (ROCHA, 2006: 42). Ou seja: na sua concepção, Chaplin é quem preza os valores da humanidade, é quem revela o papel desempenhado pelo cinema e o cineasta no contexto social. Não por coincidência, valores tão caros ao próprio Glauber na sua função de artista.

É nessa mesma particularidade de análise, pensando onde estaria o caráter do cineasta em seu papel social, que o autor de Terra em transe vai escrever o artigo "O preço da idéia", ainda na primeira parte do livro. Nele está em pauta Robert Wise, embora não apenas ele, que, segundo Glauber, é o exemplo de um artesão a serviço da indústria de filmes americanos, um cineasta que trilha tanto o caminho da obra-prima - caso de Odds against tomorrow (Homens em fúria, 1959) - como o caminho do autêntico filme tipo "chanchada" (palavras de Glauber), cujo exemplo é Two flags west (Entre dois juramentos, de 1950). Para o crítico, é possível entrever aí, nessa situação particularizada de Wise, um contexto maior, aquele que alimenta a prática do próprio artista em tempos de sociedade massiva. Seria possível fazer arte com a respiração solta, depois do sacrifício da idéia ao "mercado da inteligência" por alguns trocos? Ele responderia que o artista precisa SER, que sofre a necessidade de expressar e que os trocos recebidos pelo serviço, de algum modo, modificariam o significado e o resultado da obra mais tarde feita. Para a crítica, restava entender esse "ser cineasta": "Não temos outro caminho senão buscar a humanidade como fundamento do filme. E esta humanidade, para ser mostrada e discutida em sua verdade e com verdade, não pode ser enquadrada sob o ponto de vista de um produtor, mas de um poeta" (ROCHA, 2006: 133). Decerto, a chave desse entendimento é ético-estética: vislumbrava-se ali, precocemente - já que o artigo é originariamente de 1960 -, uma relação que seria tão marcante na obra do futuro cineasta: arte e política como faces de uma mesma moeda. Ou melhor, tiremos a moeda dessa história.

Há também momentos em que a prosa glauberiana de $O$ século se aproxima do olhar do viajante etnógrafo. O interesse, nesse momento, não reside mais naquilo que se fala da obra ou do autor em questão, mas no que o crítico deixa falar de si mesmo e de suas impressões. Glauber sai em busca do cine- 
ma e do espaço do outro, na tentativa de perscrutar as suas diferenças e os seus vazios. O autor deixa que a viagem ao mundo alheio faça-se como experiência de estranhamento, transpondo os limites do próprio mundo e fixando sua atenção além deste. Nesse sentido, é bastante modelar a crítica intitulada "From New York to Paulo Francis". Logo ao início, o crítico demarca o território da viagem: "Não adianta voar meio mundo e ficar no lugar com ares e costumes da terra natal", falando do feijãozinho, da batida, do sambinha e, dependendo do caso, ainda chorar, "numa encheção de saco monumental" (ROCHA, 2006: 138). Se o território da experiência trazido pelo autor é o da alteridade, é por essa via que o leitor deve ser levado ao passeio pelos diversos pontos da cidade. A Nova Iorque que Glauber desnuda é aquela que freqüenta os diversos espaços da cidade; suas andanças vão do experimentalismo do Living Theatre ao espaço comercial da Broadway, passando pelos encontros jazzísticos na casa de Gato Barbieri; pelos seus encontros com representantes do establishment americano ou do seu cenário resistência, caso do cineasta Robert Kramer; pelas suas avaliações do tipo americano: "Entre a dor e o nada o americano fica com a dor que fatalmente o levará ao nada atômico" (ROCHA, 2006: 145).

A segunda parte de $O$ século, dedicada ao fenômeno neo-realista, é fundamental para o entendimento das opções do artista de cinema Glauber Rocha. O cinema europeu, nessa parte, é desvendado pelas mãos do crítico, que revisita de Eisenstein a Bertolucci, passa por entrevistador intimista de grandes nomes do cinema, como Buñuel e Jean Renoir, e demarca suas afinidades, caso de Pasolini e Visconti. Para este último, é necessário notar mais de perto as razões dessas possíveis afinidades. $\mathrm{O}$ cineasta italiano, nas mãos de Glauber, é visto, entre outros papéis, como cineasta revolucionário: um artista que assumiu a estreita ligação entre a arte e a política. Haveria para o crítico, nesse contexto de análise do autor de Rocco $i$ suoi fratelli (Rocco e seus irmãos, 1960), o reconhecimento de um marxista lúcido por trás da cortina do esteta. Eis as palavras de Glauber no artigo "Visconti e os nervos de Rocco", publicado, originalmente, em 1962:

Sua [de Visconti] tomada de posição diante do mundo em que vive é uma atitude crítica, conscientemente intelectual de quem estudando a evolução da arte através dos séculos verificou que arte e política se encontraram definitiva- 
mente, não mais para trocar amabilidades ou combinar massacres, mas para interpretar a História e atingir o objetivo da Revolução. (ROCHA, 2006: 226)

Como não visualizar, nessa breve fala, aquilo que também se ajustou à vida intelectual do próprio cineasta, do qual Paulo Martins, de Terra em transe, talvez seja a mais nobre criação?

A terceira parte de $O$ século do cinema, a mais reduzida em número de páginas no livro, mas não menos profunda, dedica-se à nouvelle vague, do qual Jean-Luc Godard é um dos maiores expoentes e motivo de penetrante esforço de Glauber, nesse segmento da obra. Nos artigos, escritos entre meados dos anos 1960 e o início dos anos 1970, Godard é analisado pelo crítico como o cineasta fundador do cinema moderno, aquele que reformula todo o cinema e o reassume "do ponto onde Joyce parou com o romance" (ROCHA, 2006: 312). A obra de Godard, segundo Glauber, buscava um modo de retomar a crise da ficção contemporânea. O papel de Godard, para ele, era o de resistente aos fenômenos de mercado, de crítico da sociedade contemporânea, que observava os desencantos da vida moderna como um sociólogo e se emocionava como um poeta - os dois pesos e as duas medidas mais justas para que o artista se tornasse "o único subversivo do mundo" (ROCHA, 2006: 308). Glauber quer alertar o intelectual, sobretudo o intelectual brasileiro do início dos anos 1970, pois, para ele, assistir aos filmes de Godard não é tão tranqüilo como comer pipocas. O olhar para Godard deve residir num esforço de procura, na qual os modos da imperfeição, da angústia e da própria revolução estão sempre presentes. É uma procura que o próprio cinema brasileiro cavava à época.

Num texto publicado em 1970, e um dos últimos a compor O século, ao focalizar Le Vent d'Est (Vento do oriente, 1969), realização de Godard e de Jean-Pierre Gorin, Glauber deixou essa questão mais evidente. As posições assumidas por Godard, entre as quais se inclui a "política dos autores", eram também a base para que o Cinema Novo continuasse como força demarcatória no contexto da própria ditadura brasileira pós-68:

No caso especial do cinema, quero dizer aos colegas que agüentem firme contra as pichações, calúnias e despeitos, porque eu estou absolutamente seguro que o cinema novo brasileiro está produzindo imagens e sons daquilo que já se pode chamar cinema moderno. (ROCHA, 2006: 319) 
Convém ainda ressaltar, no âmbito desta resenha, o prefácio e a edição como um todo. Os prefácios de Ismail Xavier vêm-se tornando obras à parte na coleção Glauberiana, revelando originalidade e ineditismo no tratamento dos aspectos ainda não tangenciados pela fortuna crítica de Glauber Rocha. São análises de grande consistência teórica, aliadas à imaginação crítica, que indicam um dos nossos melhores ensaístas no âmbito dos estudos de cinema na atualidade. Para esta edição, nota-se uma preocupação exemplar, por parte da coordenação editorial, no arranjo da obra, que se materializa em alguns pontos: inserção de um apêndice com textos inéditos do crítico, que complementam os textos publicados nas três partes principais e cuja validade se torna evidente quando observamos os ensaios sobre Godard; indicação de uma fortuna crítica, com os principais textos publicados na ocasião da primeira edição do livro (ao leitor, vale debruçar-se sobre alguns deles, entre os quais recomendo o de Rogério Sganzerla); elaboração de uma lista das fontes dos textos publicados, com as respectivas datas e os meios de publicação, aspecto necessário para um melhor aproveitamento das leituras; sem contar o projeto gráfico, que segue o das publicações anteriores, sempre com inclusão de fotos ilustrativas e índice remissivo.

Por trás de $O$ século do cinema, vislumbra-se também uma possibilidade que deve ser exposta ao leitor, quase como um desafio. O livro nos impõe, em muitos momentos, a tarefa de recorrer aos filmes para uma apreciação mais dialógica com o seu autor, cabendo a nós concordar ou não com suas opiniões. O desafio, então, é escolher, a esmo ou não, e de acordo com a preferência de cada leitor, um punhado de filmes ali tratados e vê-los em paralelo às leituras dos respectivos ensaios do crítico, buscando percorrer cada narrativa cinematográfica através do olhar glauberiano.

Por fim, resta-nos recuperar uma conclusão inevitável, por conta da obra aqui resenhada, e que vai à glosa do trecho de Antonio Candido citado inicialmente: de Glauber, espera-se, geralmente, muita coisa. Antes de qualquer coisa, a crítica para ele é ato grandioso: o leão de várias cabeças devora suas vítimas e suas obras. Vale aqui a máxima: “decifra-me ou devoro-te". Engana-se aquele que não visualiza um projeto ético em tudo isso, uma ética glauberiana, em que a coerência dos atos é foco central. Trata-se da mesma coerência que o levou, até o fim da vida, a centrar suas defesas em prol de uma arte revolucionária. Cabe ao leitor o deleite de ler crítica como quem lê 
literatura glauberiana. Afinal, o século do cinema também foi o século do próprio Glauber, mais um mestre na periferia do capitalismo.

\section{Referências Bibliográficas}

CANDIDO, Antonio. Textos de intervenção. Seleção, apresentação e notas de Vinicius Dantas. São Paulo: Duas Cidades/Editora 34, 2002.

ROCHA, Glauber. O século do cinema. São Paulo: Cosac Naify, 2006. 
